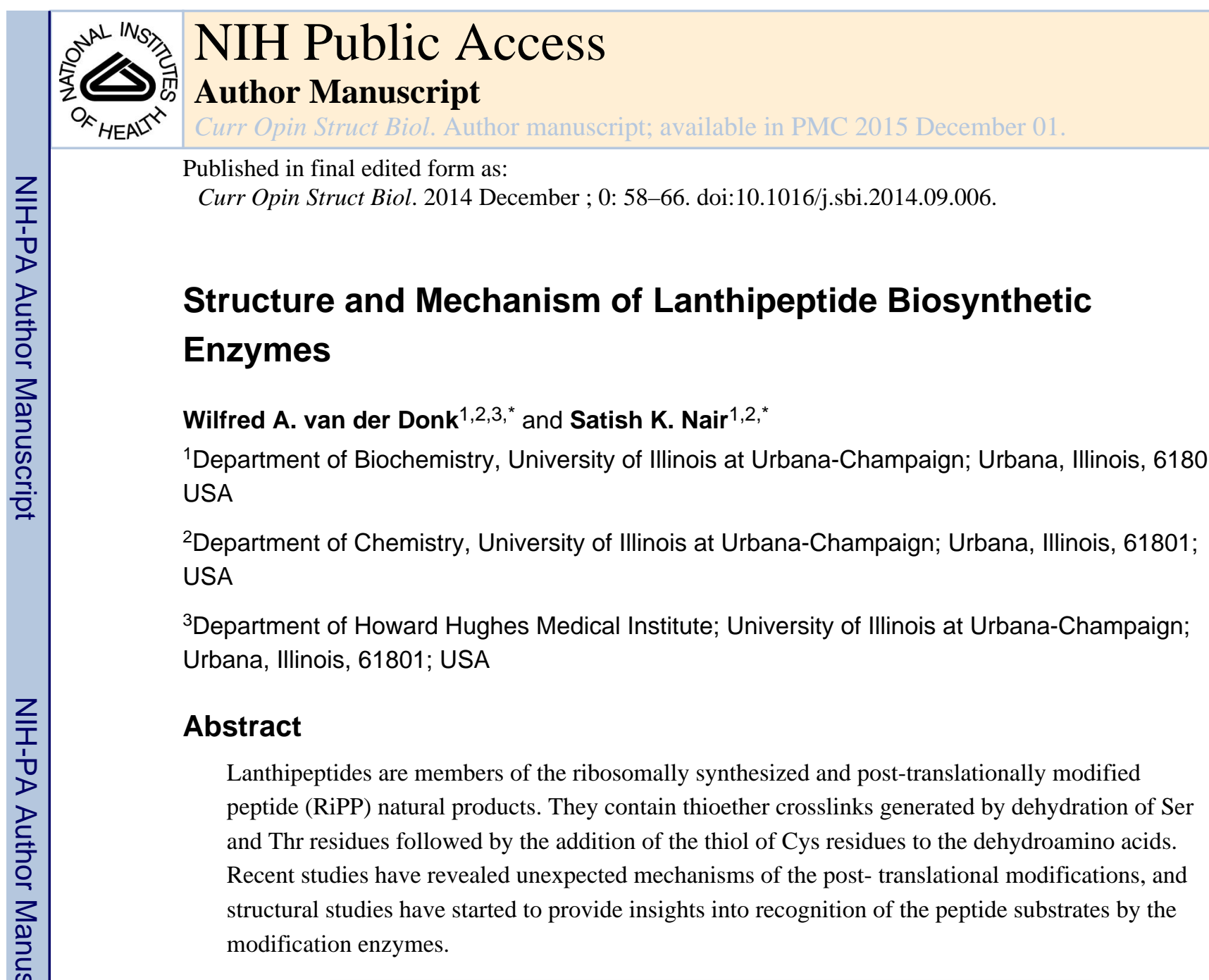

\title{
INTRODUCTION
}

The availability of large amounts of genomic data has led to the realization that microorganisms have a much larger biosynthetic capacity than previously anticipated. In turn, these findings have resulted in an expanded interest in bioactive natural products in the past decade [1]. While much of the initial research efforts have focused on non-ribosomally synthesized peptides and polyketides, recent studies of ribosomally synthesized natural products have provided a greater appreciation of the widespread occurrence of these molecules [2]. The biosynthetic modifications that produce ribosomally synthesized and post-translationally modified peptides (RiPPs) result in a vast array of structurally diverse scaffolds [3]. The genomic data have revealed that many natural products that were previously thought to have been non-ribosomally generated are, in fact, ribosomally derived peptides that have undergone extensive post-translational modifications [2]. The precursor peptide for a given RiPP can typically be demarcated into an amino-terminal leader

\footnotetext{
(c) 2014 Elsevier Ltd. All rights reserved.

*Corresponding authors: Nair, Satish K. (s-nair@life.uiuc.edu, phone: 1-217-333-0641); van der Donk, Wilfred A. (vddonk@illinois.edu, phone: 1-217-244-5360).
}

Publisher's Disclaimer: This is a PDF file of an unedited manuscript that has been accepted for publication. As a service to our customers we are providing this early version of the manuscript. The manuscript will undergo copyediting, typesetting, and review of the resulting proof before it is published in its final citable form. Please note that during the production process errors may be discovered which could affect the content, and all legal disclaimers that apply to the journal pertain. 
sequence (leader peptide) that is removed to liberate the final bioactive product, and a carboxy-terminal core peptide that is post- translationally modified into the active compound [4]. Many studies have shown that the leader peptides contain specific recognition motifs for the enzymes that carry out the post-translational modifications [5].

Lantibiotics are a class of peptide-derived antimicrobial compounds that often disrupt the integrity of Gram-positive bacterial cell walls. The most extensively studied lantibiotic is nisin, produced in certain strains of Lactococcus lactis (Figure 1). Nisin binds to lipid II (a peptidoglycan precursor) to inhibit cell wall biosynthesis, and also initiates pore formation after binding to lipid II, resulting in a multi-pronged attack on the integrity of the bacterial cell wall and membrane [6-9]. Lantibiotics are a subgroup of the lanthipeptides that are characterized by the presence of multiple lanthionine and/or 3- methyllanthionine residues that result in a crosslinked peptide backbone (Figure 1). These characteristic thioether bridges are generated by the enzymatic dehydration of Ser or Thr residues to form 2,3dehydroalanine (Dha) or (Z)-2,3-dehydrobutyrine (Dhb), followed by the enzymatic stereoselective addition of the thiol of Cys to the unsaturated amino acid. Sequence comparison of the dehydratases and cyclases allowed the grouping of lanthipeptides into four distinct classes, and phylogenetic analysis provided insights into their evolutionary origins [10]. The precursor peptides (general nomenclature LanA, i.e. NisA for nisin) of the class I lantibiotic family are post-translationally modified by two distinct modification enzymes, a dehydratase that generates the alkene moiety of Dha/Dhb (general nomenclature LanB, i.e. NisB for nisin) and a cyclase that catalyzes the addition of the Cys thiol (general nomenclature LanC, i.e. NisC for nisin; Figure 1) [11]. In contrast, a single modification enzyme with the general nomenclature of LanM is responsible for processing the precursor peptides of class II lanthipeptides [12]. LanM contains an amino-terminal dehydratase domain and a carboxy-terminal LanC-like domain (Figure 1). The third and fourth classes of lanthipeptides are also biosynthesized by a single modification enzyme (general nomenclature LanKC for class III and LanL for class IV; Figure 1). These enzymes contain an amino-terminal phospho- Ser/phospho-Thr lyase domain, a central kinase-like domain, and a carboxy-terminal LanC-like domain $[13,14]$. Notably, the carboxy-terminal LanC-like domains of class III enzymes are unique in that they lack the zinc ion (Figure 1) $[15,16]$ that is believed to activate the Cys thiol for nucleophilic attack in LanC proteins [17]. A subset of class III lanthipeptides are characterized by the presence of an unusual a,a-disubstituted tri amino acid named labionin, which enables the formation of two ring systems within a peptide chain (e.g. labyrinthopeptins, Figure 1) [18].

Additional post-translational modifications introduce further structural diversity. Examples include the installation of a 2-hydroxypropionyl group (lactate) at the amino terminus of the lantibiotic epilancin $15 \mathrm{X}$ by a dehydrogenase [19], the oxidation of one of the thioether bridges in actagardine to a sulfoxide [20,21], the hydrogenation of Dha and Dhb to generate D-amino acids in lacticin 3147 and carnolysin [22,23], the chlorination of Trp and hydroxylation of Pro in microbisporicin (NAI-107) [24], the $\beta$-hydroxylation of an aspartic acid during the biosynthesis of cinnamycin $[25,26]$, the N- glycosylation of a Trp presumably catalyzed by a glycosyltransferase within the biosynthetic cluster of the labionin-containing lanthipeptide NAI-112 [27], and the oxidative decarboxylation of the 
carboxy- terminal Cys to form an enethiolate, which subsequently cyclizes onto a Dha to form (Z)-2-aminovinyl- D-Cys [28,29]. This review focuses on those lanthipeptide biosynthetic systems for which structural information is available. Therefore, we will not discuss in detail the class II-IV lanthionine synthetases.

\section{LanB Dehydratases}

The LanB dehydratases are large enzymes, roughly $120 \mathrm{kDa}$ in size, which do not share any sequence homology to class II-IV enzymes [11]. Homologs of LanB dehydratases are found in the gene clusters of peptide natural products that are not lanthipeptides, including goadsporin and thiopeptides [30-34]. Although currently no crystallographic data are available for a LanB enzyme, recent studies have provided intriguing insights into the mechanism of dehydration [35]. A total of 28 Ala-scanning mutations of highly conserved residues in NisB were screened for activity. Notably, mutations at Arg786, Arg826 or His961 resulted in NisA products with multiple adducts with a mass of $129 \mathrm{Da}$ each, suggesting that Ser and Thr residues in the NisA substrate were activated by glutamylation (Figure 2). Conversely, Ala mutations of NisB at Arg83, Arg87, Thr89, Asp121, Asp299, Arg966 and Arg464 were inactive for dehydration activity, but could carry out conversion of the glutamylated NisA substrate to the dehydrated peptide. In concert, these experiments are consistent with NisB containing two different active sites, with one serving to catalyze glutamylation of the Ser and Thr residues of the NisA substrate, and the second active site functioning to abstract the a-proton from glutamylated Ser/Thr, resulting in elimination of the glutamate to yield the Dha/Dhb residues. Notably, the biosynthetic clusters of thiopeptides contain homologs of lantibiotic dehydratases but lack the cognate lantibiotic cyclases, consistent with the persistence of Dha/Dhb residues in the final products of these clusters [31-34]. LanB enzymes recognize a conserved "FNLD" motif in the leader peptides of their substrates $[36,37]$ and carry out dehydration with $\mathrm{N}$-to-C terminal directionality $[38,39]$.

\section{LanC Cyclases}

The crystal structure of the nisin cyclase NisC (PDB accession code: 2G0D) reveals an a/a barrel fold with a catalytically requisite zinc ion positioned at the center of the toroid (Figure 3A) [17]. There is weak but notable sequence conservation between NisC and the Cterminal domain of the bifunctional class II LanM and class IV LanL enzymes, including conservation of the His/Cys/Cys residues that function as zinc ligands (Figure 1). The zinc ion is thought to activate the Cys thiols in the precursor peptide for nucleophilic attack on the dehydroamino acids. The overall fold of NisC resembles that of the $\beta$ subunit of mammalian farnesyl transferase (PDB: 1FT1), which also contains a requisite zinc ion that activates a Cys thiol in a peptidic substrate for nucleophilic attack [40]. In farnesyl transferases, heterodimer formation between thea and $\beta$ subunits generates the binding site for the substrate and tight association between the two is necessary for function. While there is no available data on how LanC enzymes control the site selectivity of cyclization, the NisC structure shows that the loops connecting several of the helices form a structural element that resembles various eukaryotic peptide-binding domains (e.g. SH3; Figure 3A), and this element may play a role in engaging the substrate peptide and helping dictate site specificity. 
The LanC enzymes have eukaryotic counterparts termed lanthionine synthetase C-like proteins (LanCL), which are proposed to play functional roles in various signaling processes [41,42]. For example, the human LanCL2 isoform and the plant GCR2 proteins are proposed to serve as sensors for abscisic acid, and mediate downstream signaling through divergent pathways. Human LanCL1 (PDB: 3E6U) has strong structural homology to NisC but lacks the putative peptide-binding structural element (Figure 3B) [43]. LanCL1 was shown to interact with the SH3 domain of the Eps8 receptor kinase with low micromolar affinity [43], to bind glutathione [43,44], and to have anti-oxidant activity in neurons [45,46]. An interesting hypothesis has been formulated in which LanCL1 may be involved in the formation of lanthionine in human brain [47]. However, the activity of the LanCL enzymes has not been firmly established, and additional accessory proteins (similar to the farnesyltransferasea subunit) may be necessary components for an active complex.

\section{Lantibiotic Proteases}

Following the installation of Dha/Dhb by a lanthipeptide dehydratase, and the generation of the cyclic thioether linkages by a lantibiotic cyclase (and sometimes subsequent tailoring steps), the amino-terminal leader peptide is removed to yield the bioactive molecule. During the biosynthesis of class II lanthipeptides, leader peptide removal occurs concomitant with the transport of the modified precursor peptide, and is catalyzed by the papain-like Cys protease domain of LanT, a member of the ATP-binding membrane-integral cassette transporter superfamily [48]. The leader peptides of some class III lanthipeptides are removed by prolyl oligopeptidases, and one such peptidase was recently shown to only process substrates that contained a fully modified core peptide, suggesting a specificity mechanism designed to select against premature substrate cleavage [49]; similar specificity has also been observed for nisin [50].

For class I lanthipeptides, removal of the amino-terminal leader peptide is carried out by a subtilisin- like serine protease termed LanP [51]. Homology modeling, based on co-crystal structures of subtilisin BPN' (PDB: 1SBT) and thermitase (PDB: 1THM), identified roles for subsites S1 and S4 (Schechter and Berger notation; [52]) of NisP in substrate recognition. Indeed, mutations at residues Arg-1 and Ala-4 in the NisA substrate compromised substrate cleavage [53]. More recent work on the protease from the epilancin 15x biosynthetic cluster (ElxP) further subdivides the recognition elements into two clades: the (Ala/Gly-5)-(Ala-4)-x-x-(Arg-1) motif found in the C-terminus of the NisA leader sequence and related peptides (NisA class), and an (Asp/Glu-5)-(Leu/Val-4)-x-x-Gln-1 motif found in the epilancin 15x leader (ElxA) and related peptides (ElxA class) [54]. Sequence-swapping experiments demonstrated that protease specificity, within a respective clade, is governed by these five-residue motifs in the leader sequence. Importantly, the recognition determinants for leader recognition/excision by these lantibiotic proteases are distinct from the conserved motifs important for substrate recognition by the enzymes involved in (methyl)lanthionine incorporation [5]. Studies of the unrelated cyanobactin RiPPs also support a model where distinct and non-overlapping recognition elements direct recognition by the different biosynthetic enzymes [55]. 
The crystal structure of a NisP homolog from Staphylococcus aureus was recently determined by the Center for Structural Genomics of Infectious Diseases [56] (PDB: 3QFH), revealing a peptidase_S8 fold found in subtilisin-type serine proteases (Figure 3C), as expected from the strong conservation in primary sequence. The overall structure also contains a non-covalently linked amino- terminal pro-domain, which remained associated with the protease domain after autocatalytic processing. While this homolog is designated as EpiP, indicating that it is involved in the processing of the lantibiotic epidermin, this annotation is somewhat misleading as the corresponding biosynthetic cluster is not present in the organism from which the gene was cloned (S. aureus). Nonetheless, this enzyme shows strong sequence conservation with other LanP proteases, including NisP (41\% identity over 151 aligned residues) and the true EpiP from S. epidermidis 15X154 (50\% identity over 293 aligned residues).

Based on the recently reported structure, we generated a homology model of the NisP protease domain in complex with a NisA peptide and identified a canonical serine protease catalytic triad consisting of Asp259, His306 and Ser512. The substrate peptide can be accommodated into a well- defined and extended peptide-binding groove composed of multiple subsites (Figure 3D). The specificity for Arg-1 in the substrate is likely due to salt bridge formation between the guanidinium side chain of the substrate and Asp436, as well as additional interactions with the main chain carbonyls of Ala364, Ala404, and Ala438 of the protease. Notably, the retention of Thr2 in the NisA substrate would result in a clash with Tyr509, and suggests that the modified core peptide, with a Dhb at this position, may be a better substrate for the enzyme. Similarly, a number of aromatic residues including Phe477, Trp495, and Tyr509 restrict linear binding of the substrate past P3', and the binding site may be better suited to accommodate a substrate that contains a cyclic topology. These observations provide a plausible explanation for the report that NisP only removes the $\mathrm{N}$ terminal leader peptide from the modified precursor peptide NisA and not from linear NisA [50].

\section{Lantibiotic Immunity}

Lantibiotic producing strains must protect themselves against the bactericidal activity of the fully processed product. Such producer strains encode a self-immunity system consisting of two different components: a multi-pass transmembrane $\mathrm{ABC}$ transporter system consisting of the LanFEG gene products [57], and a small, single-pass immunity protein termed LanI [58]. In several instances, most notably in the nisin producer $L$. lactis, the two components work synergistically, and biochemical and genetic knock-in experiments are consistent with a model in which the LanI protein intercepts the lanthipeptide, and the LanFEG complex transports the bioactive product from the membrane to the extracellular space [59]. The ability to bind nisin was mapped to the carboxy-terminus of the NisI protein, but additional interactions between NisI and NisFEG are needed to confer complete resistance against active nisin [60]. A similar self-immunity determinant is found in the subtilin producer Bacillus subtilis ATCC6633, wherein expression of the SpaI and the SpaFEG systems are required for complete resistance. However, despite the fact that subtilin and nisin share very similar ring topologies and primary sequences, the SpaI gene does not confer resistance to nisin and the NisI gene does not function on subtilin [61]. 
The solution NMR structure of SpaI (PDB: 2LVL), in which the lipid anchor and the aminoterminal 17 residues were deleted, reveals an extended fold consisting solely of $\beta$-strands (Figure 4A) [62]. The first 32 residues, and last 4 residues of the protein are highly flexible, and the stable structure core spans Thr32 through Lys139. A longer construct of SpaI, from which the Cys1 diacylglycerol- anchoring site was deleted but the remainder of the aminoterminus was retained, was shown to bind to synthetic multilamellar liposomes, even in the absence of the lipid anchor. Moreover, titration experiments showed large changes in the chemical shifts of the amino-terminal residues and suggest a direct interaction between the first 10 residues of the protein and the membrane. Unfortunately, as lanthipeptides are generally poorly soluble in aqueous solutions, no direct structural data are available that provide information for how LanI immunity proteins would engage their cognate lantibiotics.

\section{Lantibiotic Tailoring Enzymes}

In addition to the enzymes that install the cyclic thioether linkages and carry out proteolysis of the modified lanthipeptide, a number of additional tailoring (as opposed to lanthionineforming) enzymes involved in lantibiotic maturation have been characterized. Structural data of lantibiotic tailoring enzymes have been limited and consisted until recently only of the structures of the enzymes EpiD (PDB: 1G63) [63] and MrsD (PDB: 1P3Y) [64] that catalyze Cys oxidation/decarboxylation to generate an enethiolate intermediate. These structures reveal a conserved Rossman fold architecture similar to that of flavodoxins, which assemble to form a dodecameric structure. The requisite flavin co-factor is bound with the $R e$ face exposed to solvent, and co-crystal structures show binding of a pentapeptide substrate in an extended manner (Figure 4B). The carboxy-terminal Cys of the peptide is held in place above the isoalloxazine ring of the cofactor.

More recently, the structure of the short-chain dehydrogenase ElxO involved in the maturation of epilancin 15X was solved (PDB: 4QEC) [54]. During the biosynthesis of this lanthipeptide, removal of the leader sequence exposes an amino-terminal Dha that hydrolyzes to a pyruvyl group. The ElxO dehydrogenase then catalyzes the reduction of the ketone to generate an amino-terminal lactyl group in an NADP(H)-dependent manner. Mutational analysis identified several active site residues that function in catalysis, including Tyr152 that acts as the general acid and base, Lys156 that participates as an electrostatic catalyst, and Ser139 that polarizes the substrate peptide carbonyl [54]. Although a co-crystal structure with a substrate peptide is not available, a solvent-exposed surface diagram reveals an extensive groove along the active site trajectory that could serve as the peptide-binding site (Figure 4C).

\section{CONCLUSION}

Research over the past decade has provided compelling evidence that RiPPs harbor structural and chemical complexities comparable to those found in natural products generated through non- ribosomal pathways [3]. The discovery and reconstitution of numerous RiPP pathways have resulted in an appreciation of the diversity of scaffolds that can be generated from linear peptide precursors and have prompted many successful 
genome mining exercises [65]. Biochemical and structural biological efforts are beginning to provide routes for protein engineering experiments aimed at further diversifying RiPP natural products. The combination of RiPP biosynthetic machinery with technologies such as synthetic biology or the use of suppressor tRNAs to expand the genetic code may allow for the future production of small molecules that are beyond the scope of Nature [66-69].

\section{ACKNOWLEDGEMENTS}

We thank current and former members of our laboratories who have contributed to the work that is presented here. This work was funded by grants from the National Institutes of Health (R01 GM 058822) to W.A.v.d.D, and (R01 GM 079038) to S.K.N.

\section{REFERENCES}

1. Clardy J, Fischbach MA, Walsh CT. New antibiotics from bacterial natural products. Nat Biotechnol. 2006; 24:1541-1550. [PubMed: 17160060]

2. Arnison PG, Bibb MJ, Bierbaum G, Bowers AA, Bugni TS, Bulaj G, Camarero JA, Campopiano DJ, Challis GL, Clardy J, et al. Ribosomally Synthesized and Post-translationally Modified Peptide Natural Products: Overview and Recommendations for a Universal Nomenclature. Nat. Prod. Rep. 2013; 30:108-160. [PubMed: 23165928]

3. McIntosh JA, Donia MS, Schmidt EW. Ribosomal peptide natural products: bridging the ribosomal and nonribosomal worlds. Nat. Prod. Rep. 2009; 26:537-559. [PubMed: 19642421]

4. Oman TJ, van der Donk WA. Follow the leader: the use of leader peptides to guide natural product biosynthesis. Nat Chem Biol. 2010; 6:9-18. [PubMed: 20016494]

5. Yang X, van der Donk WA. Ribosomally Synthesized and Post-Translationally Modified Peptide Natural Products: New Insights into the Role of Leader and Core Peptides during Biosynthesis. Chem. Eur. J. 2013; 19:7662-7677. [PubMed: 23666908]

6. Brötz H, Josten M, Wiedemann I, Schneider U, Götz F, Bierbaum G, Sahl H-G. Role of lipid-bound peptidoglycan precursors in the formation of pores by nisin, epidermin and other lantibiotics. Mol. Microbiol. 1998; 30:317-327. [PubMed: 9791177]

7. Breukink E, Wiedemann I, van Kraaij C, Kuipers OP, Sahl H, de Kruijff B. Use of the cell wall precursor lipid II by a pore-forming peptide antibiotic. Science. 1999; 286:2361-2364. [PubMed: 10600751]

8. Wiedemann I, Breukink E, van Kraaij C, Kuipers OP, Bierbaum G, de Kruijff B, Sahl HG. Specific binding of nisin to the peptidoglycan precursor lipid II combines pore formation and inhibition of cell wall biosynthesis for potent antibiotic activity. J. Biol. Chem. 2001; 276:1772-1779. [PubMed: 11038353]

9. Hasper HE, Kramer NE, Smith JL, Hillman JD, Zachariah C, Kuipers OP, de Kruijff B, Breukink E. A new mechanism of antibiotic action. Science. 2006; 313:1636-1637. [PubMed: 16973881]

10. Zhang Q, Yu Y, Velásquez JE, van der Donk WA. Evolution of lanthipeptide synthetases. Proc. Natl. Acad. Sci. U. S. A. 2012; 109:18361-18366. [PubMed: 23071302] Phylogenetic analysis of the 4 classes of lanthipeptide synthetases provides insights into potential evolutionary origins.

11. Knerr PJ, van der Donk WA. Discovery, biosynthesis, and engineering of lantipeptides. Annu Rev Biochem. 2012; 81:479-505. [PubMed: 22404629]

12. Siezen RJ, Kuipers OP, de Vos WM. Comparison of lantibiotic gene clusters and encoded proteins. Antonie van Leeuwenhoek. 1996; 69:171-184. [PubMed: 8775977]

13. Goto Y, Li B, Claesen J, Shi Y, Bibb MJ, van der Donk WA. Discovery of unique lanthionine synthetases reveals new mechanistic and evolutionary insights. PLoS Biol. 2010; 8:e1000339. [PubMed: 20351769]

14. Krawczyk B, Völler GH, Völler J, Ensle P, Süssmuth RD. Curvopeptin: a new lanthioninecontaining class III lantibiotic and its co-substrate promiscuous synthetase. ChemBioChem. 2012; 13:2065-2071. [PubMed: 22907786] 
15. Meindl K, Schmiederer T, Schneider K, Reicke A, Butz D, Keller S, Guhring H, Vertesy L, Wink J, Hoffmann H, et al. Labyrinthopeptins: a new class of carbacyclic lantibiotics. Angew Chem Int Ed Engl. 2010; 49:1151-1154. [PubMed: 20082397]

16. Wang H, van der Donk WA. Biosynthesis of the Class III Lantipeptide Catenulipeptin. ACS Chem. Biol. 2012; 7:1529-1535. [PubMed: 22725258]

17. Li B, Yu JP, Brunzelle JS, Moll GN, van der Donk WA, Nair SK. Structure and mechanism of the lantibiotic cyclase involved in nisin biosynthesis. Science. 2006; 311:1464-1467. [PubMed: 16527981]

18. Müller WM, Schmiederer T, Ensle P, Süssmuth RD. In vitro biosynthesis of the prepeptide of type-III lantibiotic labyrinthopeptin A2 including formation of a C-C bond as a post-translational modification. Angew. Chem. Int. Ed. Engl. 2010; 49:2436-2440. [PubMed: 20191635]

19. Velásquez JE, Zhang X, van der Donk WA. Biosynthesis of the Antimicrobial Peptide Epilancin 15X and its Unusual N-terminal Lactate Moiety. Chem Biol. 2011; 18:857-867. [PubMed: 21802007]

20. Shi Y, Bueno A, van der Donk WA. Heterologous production of the lantibiotic Ala(0)actagardine in Escherichia coli. Chem. Commun. 2012; 48:10966-10968.

21. Boakes S, Cortés J, Appleyard AN, Rudd BA, Dawson MJ. Organization of the genes encoding the biosynthesis of actagardine and engineering of a variant generation system. Mol. Microbiol. 2009; 72:1126-1136. [PubMed: 19400806]

22. Cotter PD, O’Connor PM, Draper LA, Lawton EM, Deegan LH, Hill C, Ross RP. Posttranslational conversion of L-serines to D-alanines is vital for optimal production and activity of the lantibiotic lacticin 3147. Proc. Natl. Acad. Sci. USA. 2005; 102:18584-18589. [PubMed: 16339304]

23. Lohans CT, Li JL, Vederas JC. Structure and Biosynthesis of Carnolysin, a Homologue of Enterococcal Cytolysin with d-Amino Acids. J. Am. Chem. Soc. 2014 10.1021/ja5070813.

24. Maffioli SI, Iorio M, Sosio M, Monciardini P, Gaspari E, Donadio S. Characterization of the congeners in the lantibiotic NAI-107 complex. J. Nat. Prod. 2014; 77:79-84. [PubMed: 24422756]

25. Ökesli A, Cooper LE, Fogle EJ, van der Donk WA. Nine post-translational modifications during the biosynthesis of cinnamycin. J. Am. Chem. Soc. 2011; 133:13753-13760. [PubMed: 21770392]

26. Widdick DA, Dodd HM, Barraille P, White J, Stein TH, Chater KF, Gasson MJ, Bibb MJ. Cloning and engineering of the cinnamycin biosynthetic gene cluster from Streptomyces cinnamoneus cinnamoneus DSM 40005. Proc Natl Acad Sci U S A. 2003; 100:4316-4321. [PubMed: 12642677]

27. Iorio M, Sasso O, Maffioli SI, Bertorelli R, Monciardini P, Sosio M, Bonezzi F, Summa M, Brunati C, Bordoni R, et al. A glycosylated, labionin-containing lanthipeptide with marked antinociceptive activity. ACS Chem Biol. 2014; 9:398-404. [PubMed: 24191663] This study reports the first example of a glycosylated lanthipeptide and further expands the bioactivity of lanthipeptides beyond their traditional antimicrobial activities.

28. Kupke T, Stevanovic S, Sahl HG, Götz F. Purification and characterization of EpiD, a flavoprotein involved in the biosynthesis of the lantibiotic epidermin. J Bacteriol. 1992; 174:5354-5361. [PubMed: 1644762]

29. Majer F, Schmid DG, Altena K, Bierbaum G, Kupke T. The flavoprotein MrsD catalyzes the oxidative decarboxylation reaction involved in formation of the peptidoglycan biosynthesis inhibitor mersacidin. J. Bacteriol. 2002; 184:1234-1243. [PubMed: 11844751]

30. Onaka H, Nakaho M, Hayashi K, Igarashi Y, Furumai T. Cloning and characterization of the goadsporin biosynthetic gene cluster from Streptomyces sp. TP-A0584. Microbiology. 2005; 151:3923-3933. [PubMed: 16339937]

31. Wieland Brown LC, Acker MG, Clardy J, Walsh CT, Fischbach MA. Thirteen posttranslational modifications convert a 14-residue peptide into the antibiotic thiocillin. Proc. Natl. Acad. Sci. U.S.A. 2009; 106:2549-2553. [PubMed: 19196969]

32. Kelly WL, Pan L, Li C. Thiostrepton biosynthesis: prototype for a new family of bacteriocins. J. Am. Chem. Soc. 2009; 131:4327-4334. [PubMed: 19265401]

33. Liao R, Duan L, Lei C, Pan H, Ding Y, Zhang Q, Chen D, Shen B, Yu Y, Liu W. Thiopeptide biosynthesis featuring ribosomally synthesized precursor peptides and conserved posttranslational modifications. Chem. Biol. 2009; 16:141-147. [PubMed: 19246004] 
34. Morris RP, Leeds JA, Naegeli HU, Oberer L, Memmert K, Weber E, Lamarche MJ, Parker CN, Burrer N, Esterow S, et al. Ribosomally Synthesized Thiopeptide Antibiotics Targeting Elongation Factor Tu. J. Am. Chem. Soc. 2009:5946-5955. [PubMed: 19338336]

35. Garg N, Salazar-Ocampo LM, van der Donk WA. In vitro activity of the nisin dehydratase NisB. Proc Natl Acad Sci U S A. 2013; 110:7258-7263. [PubMed: 23589847]

36. Plat A, Kluskens LD, Kuipers A, Rink R, Moll GN. Requirements of the engineered leader peptide of nisin for inducing modification, export, and cleavage. Appl. Environ. Microbiol. 2011; 77:604611. [PubMed: 21097596]

37. Khusainov R, Heils R, Lubelski J, Moll GN, Kuipers OP. Determining sites of interaction between prenisin and its modification enzymes NisB and NisC. Mol. Microbiol. 2011; 82:706-718. [PubMed: 22011325] Pulldown of NisB and NisC with the precursor NisA was used to determine residues on NisA that are important for substrate binding.

38. Lubelski J, Khusainov R, Kuipers OP. Directionality and Coordination of Dehydration and Ring Formation during Biosynthesis of the Lantibiotic Nisin. J. Biol. Chem. 2009; 284:25962-25972. [PubMed: 19620240]

39. Zhang Q, Ortega M, Shi Y, Wang H, Melby JO, Tang W, Mitchell DA, van der Donk WA. Structural investigation of ribosomally synthesized natural products by hypothetical structure enumeration and evaluation using tandem MS. Proc. Natl. Acad. Sci. U. S. A. 2014; 111:1203112036. [PubMed: 25092299]

40. Park HW, Boduluri SR, Moomaw JF, Casey PJ, Beese LS. Crystal structure of protein farnesyltransferase at 2.25 angstrom resolution. Science. 1997; 275:1800-1804. [PubMed: 9065406]

41. Blisnick T, Vincensini L, Barale JC, Namane A, Braun Breton C. LANCL1, an erythrocyte protein recruited to the Maurer's clefts during Plasmodium falciparum development. Mol Biochem Parasitol. 2005; 141:39-47. [PubMed: 15811525]

42. Sturla L, Fresia C, Guida L, Bruzzone S, Scarfi S, Usai C, Fruscione F, Magnone M, Millo E, Basile $\mathrm{G}$, et al. LANCL2 is necessary for abscisic acid binding and signaling in human granulocytes and in rat insulinoma cells. J Biol Chem. 2009; 284:28045-28057. [PubMed: 19667068]

43. Zhang W, Wang L, Liu Y, Xu J, Zhu G, Cang H, Li X, Bartlam M, Hensley K, Li G, et al. Structure of human lanthionine synthetase C-like protein 1 and its interaction with Eps8 and glutathione. Genes Dev. 2009; 23:1387-1392. [PubMed: 19528316]

44. Chung CH, Kurien BT, Mehta P, Mhatre M, Mou S, Pye QN, Stewart C, West M, Williamson KS, Post J, et al. Identification of lanthionine synthase C-like protein-1 as a prominent glutathione binding protein expressed in the mammalian central nervous system. Biochemistry. 2007; 46:3262-3269. [PubMed: 17305318]

45. Huang C, Chen M, Pang D, Bi D, Zou Y, Xia X, Yang W, Luo L, Deng R, Tan H, et al. Developmental and Activity-Dependent Expression of LanCL1 Confers Antioxidant Activity Required for Neuronal Survival. Dev. Cell. 2014; 30:479-487. [PubMed: 25158856]

46. Zhong WX, Wang YB, Peng L, Ge XZ, Zhang J, Liu SS, Zhang XN, Xu ZH, Chen Z, Luo JH. Lanthionine synthetase $\mathrm{C}$-like protein 1 interacts with and inhibits cystathionine beta-synthase: a target for neuronal antioxidant defense. J. Biol. Chem. 2012; 287:34189-34201. [PubMed: 22891245]

47. Hensley K, Venkova K, Christov A. Emerging biological importance of central nervous system lanthionines. Molecules. 2010; 15:5581-5594. [PubMed: 20714314]

48. Håvarstein LS, Diep DB, Nes IF. A family of bacteriocin ABC transporters carry out proteolytic processing of their substrates concomitant with export. Mol. Microbiol. 1995; 16:229-240. [PubMed: 7565085]

49. Völler GH, Krawczyk B, Ensle P, Süssmuth RD. Involvement and unusual substrate specificity of a prolyl oligopeptidase in class III lanthipeptide maturation. J Am Chem Soc. 2013; 135:74267429. [PubMed: 23651048] This report describes the first example of a Pro oligopeptidase involved in leader peptide removal.

50. Kuipers A, De Boef E, Rink R, Fekken S, Kluskens LD, Driessen AJ, Leenhouts K, Kuipers OP, Moll GN. NisT, the transporter of the lantibiotic nisin, can transport fully modified, dehydrated 
and unmodified prenisin and fusions of the leader peptide with non-lantibiotic peptides. J. Biol. Chem. 2004; 279:22176-22182. [PubMed: 15044440]

51. van der Meer JR, Polman J, Beerthuyzen MM, Siezen RJ, Kuipers OP, De Vos WM. Characterization of the Lactococcus lactis nisin A operon genes nisP, encoding a subtilisin-like serine protease involved in precursor processing, and nisR, encoding a regulatory protein involved in nisin biosynthesis. J Bacteriol. 1993; 175:2578-2588. [PubMed: 8478324]

52. Schechter I, Berger A. On the size of the active site in proteases. I. Papain. Biochem Biophys Res Commun. 1967; 27:157-162. [PubMed: 6035483]

53. Siezen RJ, Rollema HS, Kuipers OP, de Vos WM. Homology modelling of the Lactococcus lactis leader peptidase NisP and its interaction with the precursor of the lantibiotic nisin. Protein Eng. 1995; 8:117-125. [PubMed: 7630881]

54. Ortega MA, Velásquez JE, Garg N, Zhang Q, Joyce RE, Nair SK, van der Donk WA. Substrate Specificity of the Lanthipeptide Peptidase ElxP and the Oxidoreductase ElxO. ACS Chem. Biol. 2014; 9:1718-1725. [PubMed: 24866416]

55. Sardar D, Pierce E, McIntosh JA, Schmidt EW. Recognition Sequences and Substrate Evolution in Cyanobactin Biosynthesis. ACS Synth. Biol. 2014 10.1021/sb500019b.

56. Kuhn ML, Prachi P, Minasov G, Shuvalova L, Ruan J, Dubrovska I, Winsor J, Giraldi M, Biagini M, Liberatori S, et al. Structure and protective efficacy of the Staphylococcus aureus autocleaving protease EpiP. FASEB J. 2014; 28:1780-1793. [PubMed: 24421400] This report describes the structure of a protease with high sequence homology with LanP proteases that remove lanthipeptide leader sequences.

57. Peschel A, Götz F. Analysis of the Staphylococcus epidermidis genes epiF, -E, and -G involved in epidermin immunity. J Bacteriol. 1996; 178:531-536. [PubMed: 8550476]

58. Reis M, Eschbach-Bludau M, Iglesias-Wind MI, Kupke T, Sahl HG. Producer immunity towards the lantibiotic Pep5: identification of the immunity gene pepI and localization and functional analysis of its gene product. Appl Environ Microbiol. 1994; 60:2876-2883. [PubMed: 8085827]

59. Stein T, Heinzmann S, Solovieva I, Entian KD. Function of Lactococcus lactis nisin immunity genes nisI and nisFEG after coordinated expression in the surrogate host Bacillus subtilis. J Biol Chem. 2003; 278:89-94. [PubMed: 12379654]

60. Takala TM, Saris PE. C terminus of NisI provides specificity to nisin. Microbiology. 2006; 152:3543-3549. [PubMed: 17159206]

61. Draper LA, Ross RP, Hill C, Cotter PD. Lantibiotic immunity. Curr Protein Pept Sci. 2008; 9:39_ 49. [PubMed: 18336322]

62. Christ NA, Bochmann S, Gottstein D, Duchardt-Ferner E, Hellmich UA, Dusterhus S, Kotter P, Guntert P, Entian KD, Wohnert J. The First structure of a lantibiotic immunity protein, SpaI from Bacillus subtilis, reveals a novel fold. J Biol Chem. 2012; 287:35286-35298. [PubMed: 22904324] NMR structure of SpaI, providing the first structural insights into lantibiotic immunity proteins.

63. Blaesse M, Kupke T, Huber R, Steinbacher S. Crystal structure of the peptidyl-cysteine decarboxylase EpiD complexed with a pentapeptide substrate. EMBO J. 2000; 19:6299-6310. [PubMed: 11101502]

64. Blaesse M, Kupke T, Huber R, Steinbacher S. Structure of MrsD, an FAD-binding protein of the HFCD family. Acta Crystallogr D Biol Crystallogr. 2003; 59:1414-1421. [PubMed: 12876343]

65. Velásquez JE, van der Donk WA. Genome mining for ribosomally synthesized natural products. Curr. Opin. Chem. Biol. 2011; 15:11-21. [PubMed: 21095156]

66. Shi Y, Yang X, Garg N, van der Donk WA. Production of lantipeptides in Escherichia coli. J. Am. Chem. Soc. 2011; 133:2338-2341.

67. Tianero MD, Donia MS, Young TS, Schultz PG, Schmidt EW. Ribosomal route to small-molecule diversity. J. Am. Chem. Soc. 2012; 134:418-425. [PubMed: 22107593]

68. van Heel AJ, Mu D, Montalban-Lopez M, Hendriks D, Kuipers OP. Designing and producing modified, new-to-nature peptides with antimicrobial activity by use of a combination of various lantibiotic modification enzymes. ACS Synth. Biol. 2013; 2:397-404. [PubMed: 23654279] This report describes the first combination of lanthipeptide biosynthetic enzymes from different organisms to make new hybrid compounds. 
69. Oldach F, Al Toma R, Kuthning A, Caetano T, Mendo S, Budisa N, Süssmuth RD. Congeneric Lantibiotics from Ribosomal In Vivo Peptide Synthesis with Noncanonical Amino Acids. Angew. Chem. Int. Ed. 2012; 51:415-418. 


\section{Highlights}

- Dehydration of precursor peptides by class I lanthipeptide dehydratases involves glutamylation of Ser and Thr residues

- The first structural insights into recognition of the substrate by lanthipeptide proteases have been reported

- Structure of an immunity protein helps understand self-protection by lantibiotic producing bacteria

- The structure of the dehydrogenase ElxO provides insights into the biosynthesis of epilancin $15 \mathrm{X}$ 


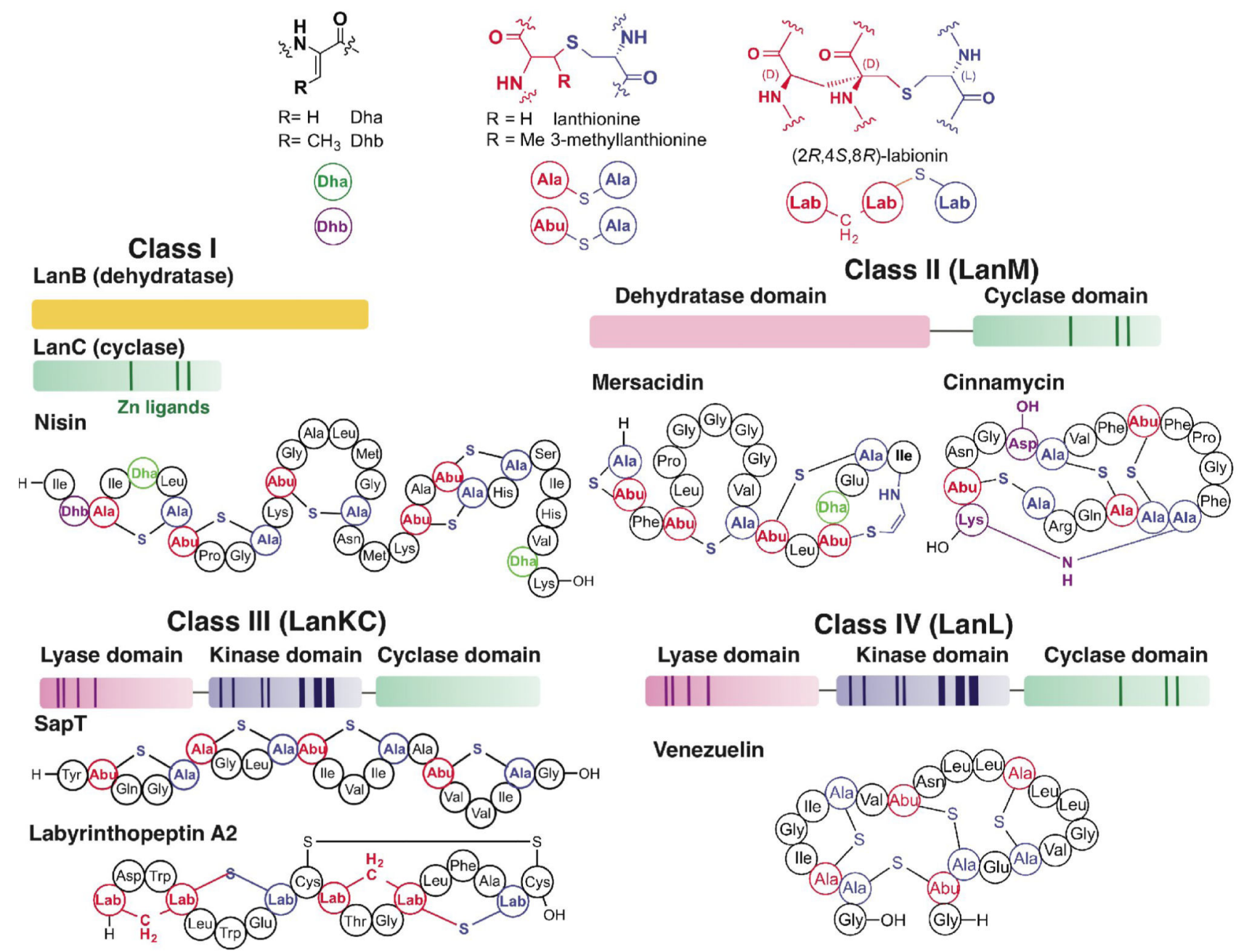

Figure 1.

Structures of the canonical post-translational modifications in lanthipeptides, overview of the four classes of lanthipeptide biosynthesis, and structures of representative members. The class I lantibiotics, such as nisin, are generated by two independent enzymes (LanB dehydratase and LanC cyclase); class II molecules like mersacidin and cinnamycin are biosynthesized by a bifunctional enzyme that contains both dehydration and cyclization activities; the biosynthesis of class III molecules, such as SapT or labyrinthopeptin A2, is carried out by a single protein that has lyase, kinase, and cyclase domains but lacks the signature zinc-ligands in the cyclase domain. Some class III lanthipeptides contain labionin moieties; class IV lantibiotics, such as venezuelin are generated by an enzyme that also contains lyase and kinase domains but a LanC-like cyclase domain that contains the metal ligands. 
NisA
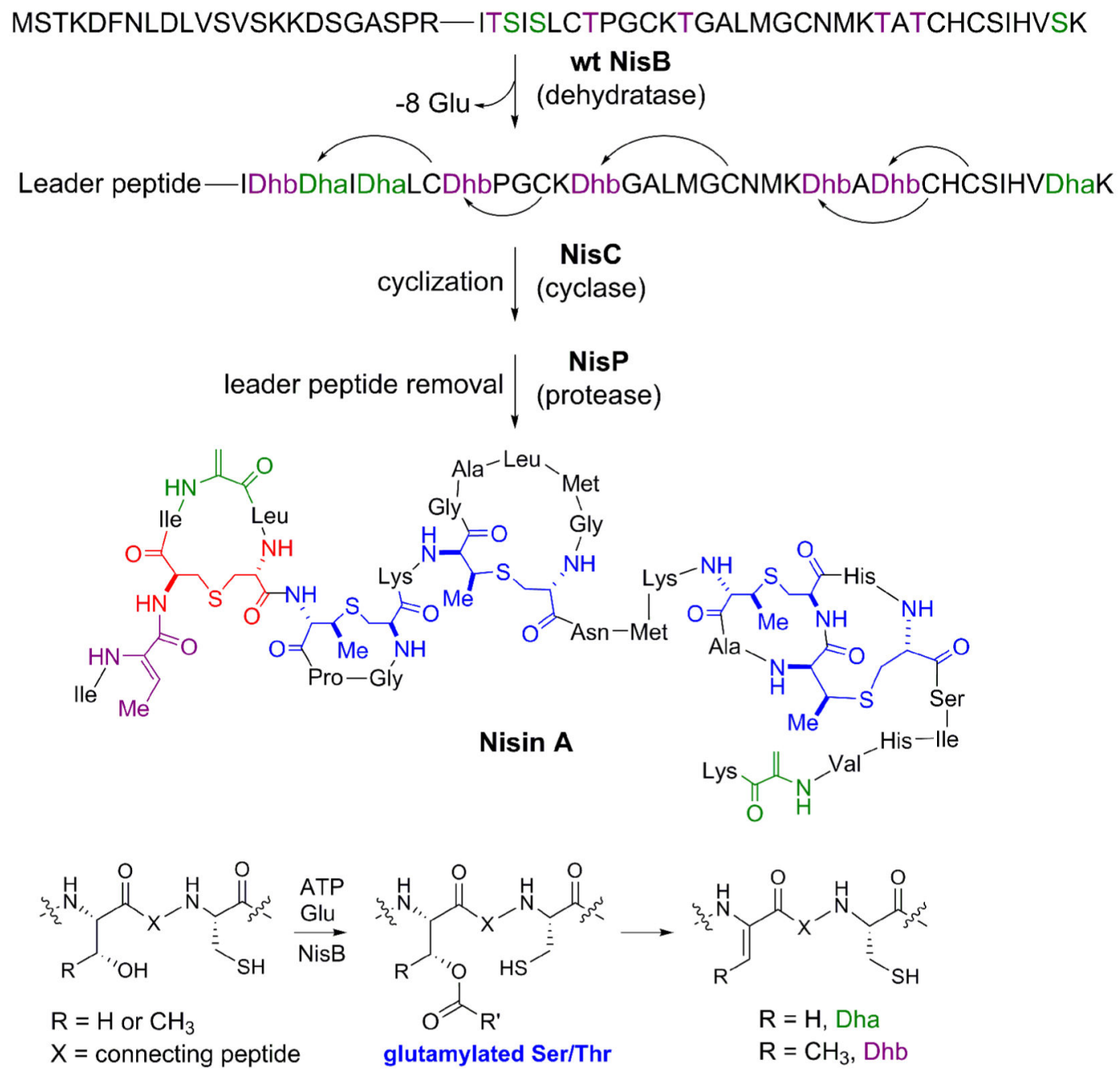

Figure 2.

The biosynthesis of the class I lantibiotic nisin is catalyzed by a dehydratase NisB and a cyclase NisC. The activation of Ser/Thr by the addition of glutamate was uncovered by analysis of NisB mutants. Wild type NisB is able to eliminate the glutamates to generate the dehydroamino acid residues. During normal catalysis, the glutamates are cryptic and never observed. The NisC cyclase carries out cyclization in a zinc-dependent manner but the molecular mechanism that governs site specificity for thioether formation is not yet known. The leader peptide is removed from the modified peptide by a specific protease to yield the bioactive natural product. Lanthionines are shown in red, methyllanthionines in blue. 
A

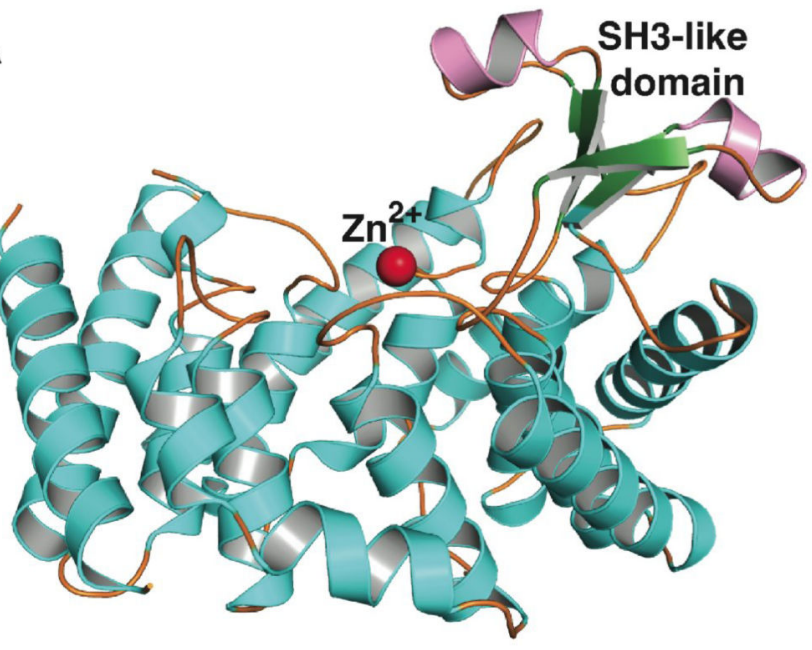

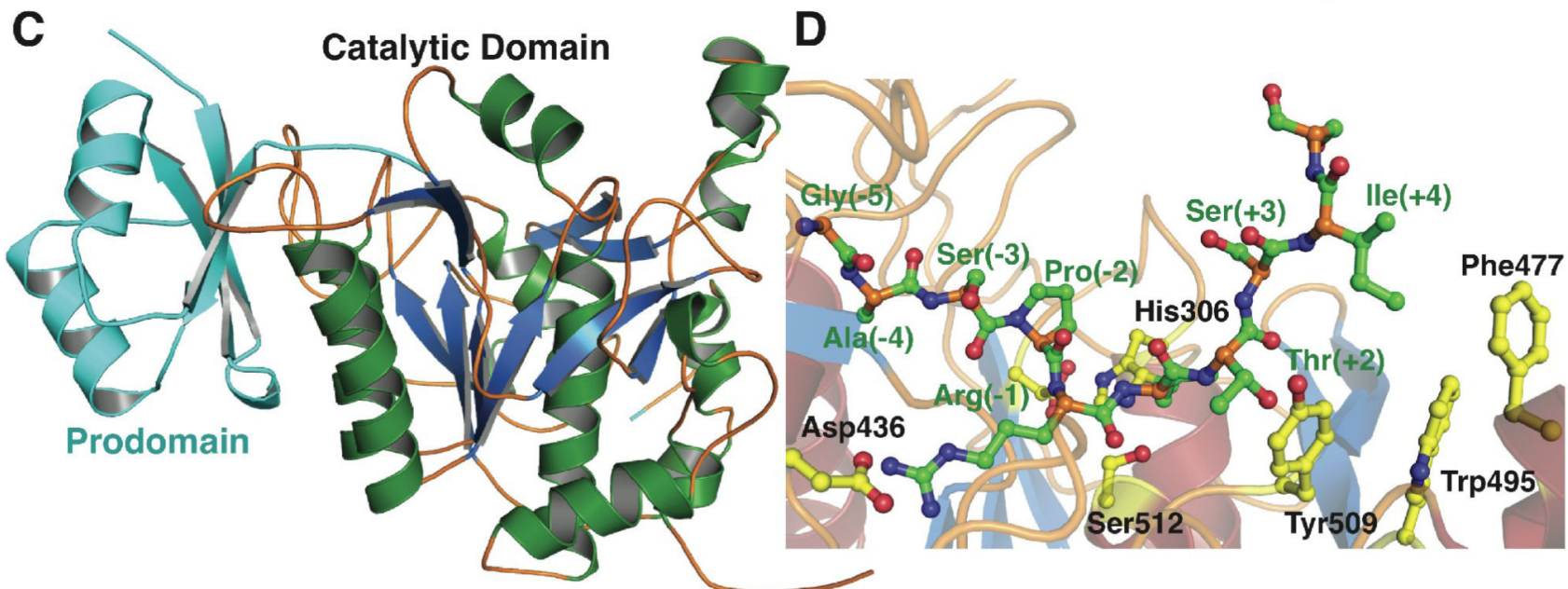

B

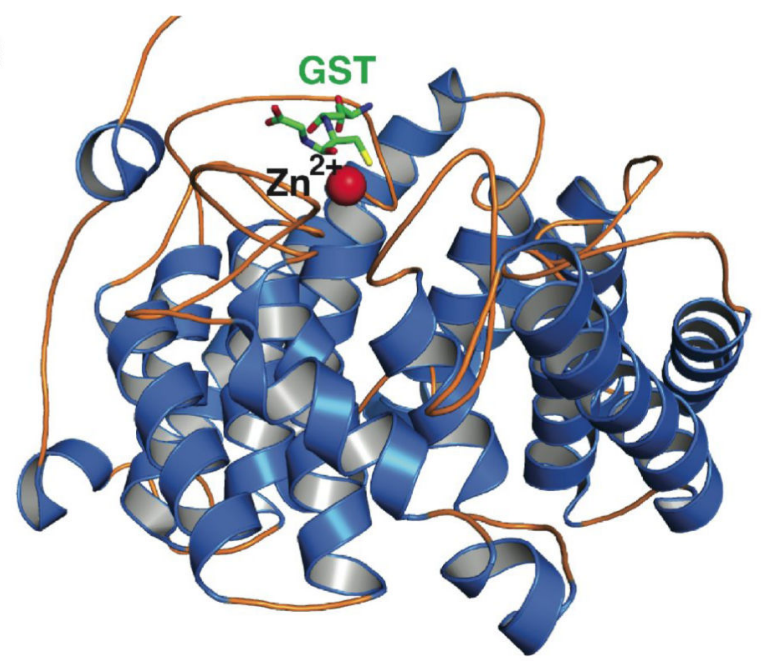

Figure 3.

Structures of the nisin cyclase $\mathrm{NisC}$, the eukaryotic lanthionine synthase C-like protein LanCL1, a lanthipeptide protease-like protein from S. aureus, and the protease NisP. (A) NisC contains a structural element resembling eukaryotic peptide binding domains that is missing in the LanCL proteins such as LanCL1 (B). (C) Crystal structure of the orphan lantibiotic protease homolog from S. aureus with the prodomain colored in cyan and the catalytic domain colored in green and blue. (D) A model of the NisP protease in complex with an unmodified NisA peptide substrate, generated using the $S$. aureus orphan enzyme as a template. Protease residues are shown in yellow and substrate residues are shown in green. The presence of an aromatic wall that blocks the carboxy- terminal end of the substratebinding site may facilitate a preference for modified substrates containing a thioether cycle. 


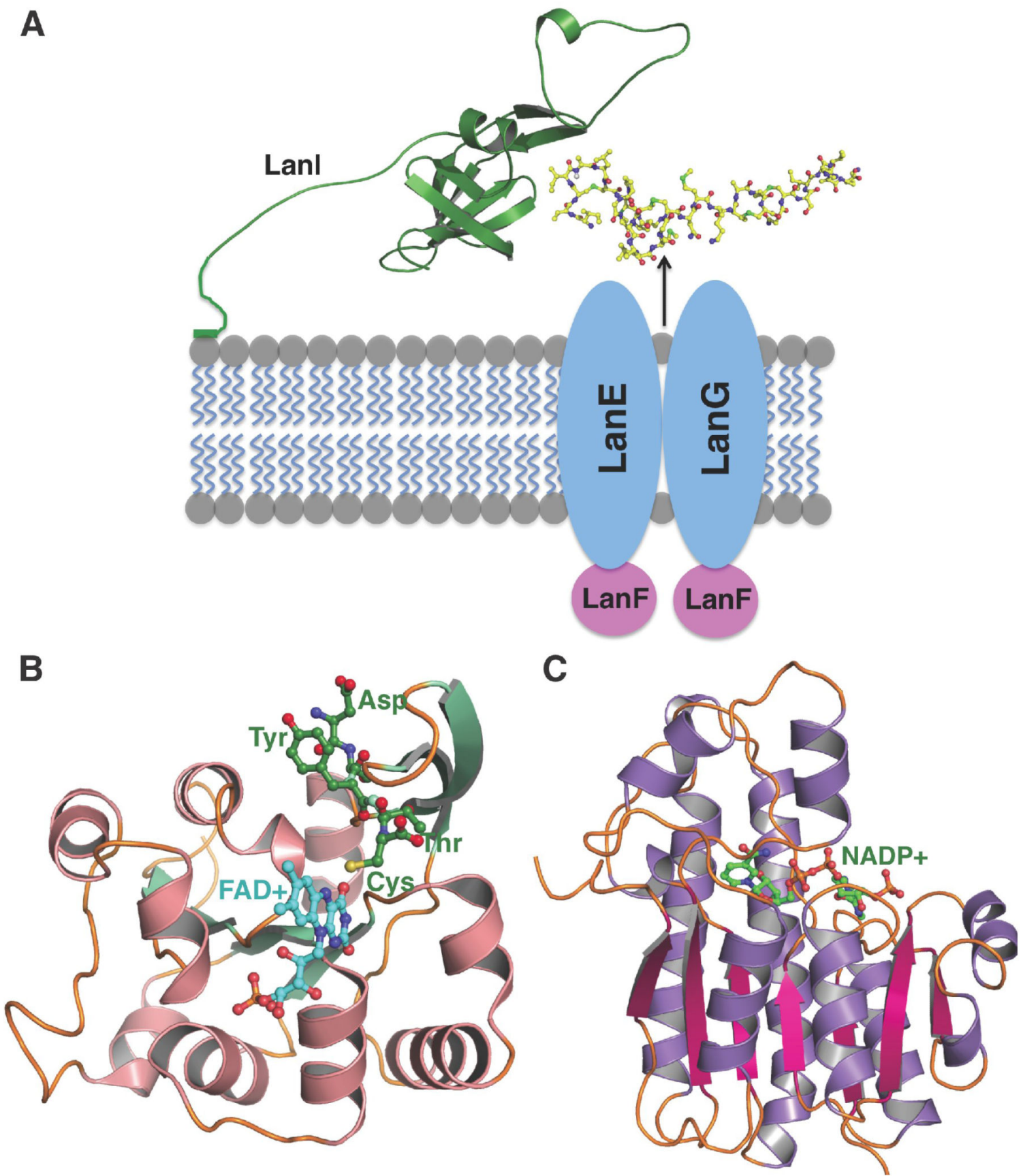

Figure 4.

Structures of lanthipeptide immunity proteins and tailoring enzymes. (A) The coordinated actions of the LanFEG transport system and the LanI lantibiotic-binding protein confer selfimmunity against lantibiotic toxicity in producing strains. The depicted orientation of the immunity protein is based upon the NMR structure of SpaI and biochemical data that suggest that the amino-terminus of the immunity protein binds to lipid membranes even in the absence of a covalent anchor. Presumably, the immunity protein would act to bind directly to lantibiotics that are then expelled from the cell through the FEG transport system. 
While several lanthipeptide tailoring enzymes have been characterized, structural data are available only for (B) oxidative decarboxylases, illustrated for EpiD (shown in pink and green) involved in the maturation of epidermin, and (C) the short-chain dehydrogenase ElxO that processes epilancin $15 \mathrm{X}$ (shown in purple and red). 